\title{
In vitro anti-microbial activity of the Cuban medicinal plants Simarouba glauca DC, Melaleuca leucadendron L and Artemisia absinthium L
}

\author{
Aymé Fernández-Calienes Valdés/ ${ }^{+}$, Judith Mendiola Martínez, Ramón Scull Lizama', \\ Marieke Vermeersch'², Paul Cos², Louis Maes² \\ Departamento de Parasitología, Instituto de Medicina Tropical Pedro Kourí, Autopista Novia del Mediodía Km 61⁄2, Marianao 13, \\ La Habana, Cuba ${ }^{1}$ Departamento de Farmacia, Instituto de Farmacia y Alimentos, Universidad de La Habana, La Habana, Cuba \\ ${ }^{2}$ Laboratory for Microbiology, Parasitology and Hygiene, University of Antwerp, Antwerp, Belgium ${ }^{3}$ Animal Health Department, \\ Institute of Tropical Medicine of Antwerp, Antwerp, Belgium
}

In the present study, an extensive in vitro antimicrobial profiling was performed for three medicinal plants grown in Cuba, namely Simarouba glauca, Melaleuca leucadendron and Artemisia absinthium. Ethanol extracts were tested for their antiprotozoal potential against Trypanosoma b. brucei, Trypanosoma cruzi, Leishmania infantum and Plasmodium falciparum. Antifungal activities were evaluated against Microsporum canis and Candida albicans whereas Escherichia coli and Staphylococcus aureus were used as test organisms for antibacterial activity. Cytotoxicity was assessed against human MRC-5 cells. Only M. leucadendron extract showed selective activity against microorganisms tested. Although S. glauca exhibited strong activity against all protozoa, it must be considered non-specific. The value of integrated evaluation of extracts with particular reference to selectivity is discussed.

Key words: plants - antimicrobial activity - cytotoxicity - selectivity

Plants have always been among the common sources of medicines, either processed as traditional preparations or used to extract pure active principles. Because of the large chemical diversity among natural products, many research groups screen plant extracts in their search for new promising therapeutic candidates for infectious diseases. Over the last 20 years, the Ministry of Public Health (MPH) in Cuba has promoted pharmacological and toxicological evaluation of widely used medicinal plant species to be included in the National Health System (NHS) as raw vegetal material or herbal medicine (Abreu et al. 2004). Although malaria has been eradicated from Cuba since 1973, revision of ethnobotanical information revealed a few plant species that were traditionally used as antimalarial. In a previous study, ethanolic extracts of three plants used in Cuba as antipyretic and/or as antimalarial (Simarouba glauca, Melaleuca leucadendron and Artemisia absinthium) were found active in vitro against Plasmodium falciparum and marginally active in vivo against Plasmodium berghei (Rodríguez et al. 2006). In addition, Cuban folk medicine information also shows several other medicinal uses for these plants, including antihelminthic, antidysenteric and antiherpetic action (Roig 1974). Similarly, the anti-infective properties of these plants have been confirmed by several other research groups (Caceres et al. 1990, Franssen et al. 1997, Farag et al. 2004).

+ Corresponding author: ayme@ipk.sld.cu

Received 15 May 2008

Accepted 7 August 2008
Since selectivity must be part of a proper in vitro pharmacological evaluation, we decided to screen the crude extracts of the three plants, prior to any fractionation process, against a broad panel of micro-organisms, including the malaria parasite in combination with a parallel cytotoxicity evaluation, as yet undetermined. More specifically, the Cuban "antimalarial" plant extracts were examined for their cytotoxicity on human fibroblasts and for antitrypanosomal, antileishmanial, antifungal and antibacterial activities.

Plant species identification and collection was made by a botanical specialist in the Cuban National Garden, Havana City, on August 2006. The garden entry code of studied specimens was recorded (S. glauca 8300710, M. leucadendron 8501918 and A. absinthium 9700169). Plant branches were carefully collected to avoid contamination with other parts of the plant and foreign materials. Vegetal material was dried in a ventilated incubator at $30^{\circ} \mathrm{C}$ and subsequently milled into coarse particles of about $5 \mathrm{~mm}$.

Liquid extraction of the dried processed plant material was achieved by maceration for seven days (MSP 1991) in $80 \%$ ethanol. The solvent was removed by evaporation at reduced pressure for $24 \mathrm{~h}$ and the remaining residue was frozen at $-70^{\circ} \mathrm{C}$ for $48 \mathrm{~h}$ before lyophilization. Stock solutions of each lyophilized sample were reconstituted in $100 \%$ dimethyl sulphoxide (DMSO) at $20 \mathrm{mg} / \mathrm{mL}$ and stored at $4^{\circ} \mathrm{C}$ until use.

The experiments were performed in 96-well plates (Greiner), each plate containing 16 compounds at fourfold dilutions in a dose-titration range of $64 \mu \mathrm{g} / \mathrm{mL}$ to $0.25 \mu \mathrm{g} / \mathrm{mL}$. Dilutions were carried out by a programmable precision robotic station (BIOMEK 2000, Beckman, USA). Each plate also contained medium-controls (blanks: 0\% growth), infected untreated controls (nega- 
tive control: $100 \%$ growth) and reference controls (positive control). Tests were run in duplicate.

For the different antimicrobial tests, appropriate reference drugs were used as positive control: chloroquine sulphate and artemether for $P$. falciparum, amphotericin B for Leishmania infantum, nifurtimox for Trypanosoma cruzi, suramin and pentamidine for Trypanosoma brucei, myconazol and terbinafine for Microsporum canis, myconazol and flucytosine for Candida albicans, doxycycline and norfloxacin for Escherichia coli and doxycycline and rifampicin for Staphylococcus aureus. All reference drugs were either obtained from Sigma or from WHO-TDR. Strains used in this study were: chloroquine-suceptible $P$. falciparum Ghana, $T$. b. brucei Squib-427 (suramin-sensitive), T. cruzi Tulahuen-LacZ, clone $\mathrm{C} 4$ (nifurtimox-sensitive), L. infantum amastigotes MHOM/MA(BE)/67, E. coli ATCC-8739 and S. aureus ATCC-6538. MRC-5 cells, human fetal lung fibroblast, were the cell line for a cytotoxicity assay. The values were calculated from the dose-response curves using the Statview ${ }^{\mathrm{TM}}$ software package.

The integrated panel of microbial screens for the present study and the standard screening methodologies were adopted as have been described by Cos et al. (2006). Activities of compounds were expressed as inhibitory concentration $50 \%$, i.e. the concentration of extract that inhibits $50 \%$ of microbial growth $\left(\mathrm{IC}_{50}\right)$ and human cell growth $\left(\mathrm{CC}_{50}\right)$.

All extracts were screened in vitro for their antiprotozoal activity against $P$. falciparum, $L$. infantum, $T$. cruzi and $T$. b. brucei. The $\mathrm{IC}_{50}$ values are listed in Table I. $S$. glauca extract exhibited the strongest inhibitory activity with $\mathrm{IC}_{50}$ values below $3 \mu \mathrm{g} / \mathrm{mL}$ against all tested protozoa. M. leucadendron and A. absinthium showed some inhibitory activity against $T . b$. brucei and almost none against $P$. falciparum and T. cruzi. The selectivity indices ( $\mathrm{SI}=$ ratio of cytotoxicity to biological activity) are presented in Table II. In general, low selectivity was found, not exceeding $5 \mathrm{X}$, for the observed antitrypanosomal activities against $T$. b. brucei.

The activities of the extracts on bacteria, yeasts and dermatophytes are presented in Table III. M. leucadendron extract showed marginal antifungal activity against $M$. canis. The highest activity was recovered for $S$. glauca against $M$. canis with an $\mathrm{IC}_{50}$ of $2 \mu \mathrm{g} / \mathrm{mL}$. No antibacterial or antifungal activity was found for $A$. $a b$ sinthium in the assayed concentrations.

To join the current initiative by the Cuban MPH to inventory pharmacological and toxicological evaluation of medicinal plant species for inclusion in the NHS, three Cuban medicinal plants (S. glauca, M. leucadendron and A. absinthium) that were previously identified for antimalarial activity (Rodríguez et al. 2006) were re-evaluated against a more extensive panel of micro-organisms, including other parasitic protozoa, bacteria, yeasts and dermatophytes. A major drawback of the published data is the lack of selectivity evaluation via parallel cytotoxicity testing; this issue is specifically addressed in the present study, in which crude ethanolic extracts were tested in an integrated manner.
TABLE I

IC50 values of plant extracts against protozoa

\begin{tabular}{lccccc}
\hline $\begin{array}{l}\text { M. leucadendron } \\
\text { S. glauca }\end{array}$ & $\begin{array}{c}31.3 \\
<0.25\end{array}$ & $\begin{array}{c}> \\
\text { St.7 }\end{array}$ & $\begin{array}{c}18.0 \\
<0.25\end{array}$ & $\begin{array}{c}4.1 \\
<0.25\end{array}$ & $\begin{array}{c}20.0 \\
<0.25\end{array}$ \\
\hline Standards & & & IC50 $(\mu \mathrm{M})$ & \\
\hline Chloroquine & 0.0245 & - & - & - & - \\
Doxycycline & 1.0 & - & - & - & - \\
Artemether & 0.0165 & - & - & - & - \\
Amphotericine B & - & 0.54 & - & - & - \\
Nifurtimox & - & - & 0.841 & - & - \\
Suramin & - & - & - & 0.033 & - \\
Melarsoprol & - & - & - & 0.018 & - \\
Pentamidine & - & - & - & 0.033 & - \\
\hline
\end{tabular}

TABLE II

Selectivity index of antiprotozoal activity

\begin{tabular}{|c|c|c|c|c|}
\hline Extracts & falciparum & L. infantum & T. cruzi & i Tb. brucei \\
\hline A. absinthium & 1.28 & - & $<1$ & 2.87 \\
\hline M. leucadendron & $<1$ & - & 1.11 & 4.84 \\
\hline S. glauca & nd & $<1$ & nd & nd \\
\hline
\end{tabular}

nd: not determined.

TABLE III

IC50 values of plant extracts against fungi and bacteria

\begin{tabular}{lcccc}
\hline & \multicolumn{4}{c}{$\mathrm{IC50}(\mu \mathrm{g} / \mathrm{mL})$} \\
\cline { 2 - 5 } Extracts & M. canis & C. albicans & E. coli & S. aureus \\
\hline A. absinthium & $>64$ & $>64$ & $>64$ & $>64$ \\
M. leucadendron & 13.0 & $>64$ & $>64$ & 36.0 \\
S. glauca & 2.0 & $>64$ & $>64$ & $>64$ \\
\hline & \multicolumn{5}{c}{$\mathrm{IC50}(\mu \mathrm{M})$} \\
Myconazol & 0.161 & 3.5 & \\
Terbinafine & 0.167 & - & & \\
Flucytosine & - & 0.1627 & \\
Doxycycline & - & - & 0.527 & 0.342 \\
Rifampicine & - & - & - & 0.0805 \\
Norfloxacin & - & - & 0.029 & - \\
\hline
\end{tabular}

Efficacy parameters for anti-infective activity have been proposed for pure compounds (Pink et al. 2005, Cos et al. 2006) and crude extracts (Cos et al. 2006). For crude extracts, $\mathrm{IC}_{50}$ values should certainly be below $100 \mu \mathrm{g} / \mathrm{mL}$, but still depend on the model. For cytotoxicity and referring to WHO criteria, Dua et al. (2004) classified plant extracts as non-cytotoxic if the $\mathrm{CC}_{50}$ was $\geq 16 \mu \mathrm{g} / \mathrm{mL}$. For pure compounds, relevant biological efficacy must have a selectivity index of at least 10 (Pink et al. 2005). Unfortunately, a definite SIvalue for crude plant extracts is more difficult to establish as the actual content if the active ingredient is not known. In addition, a plant extract may contain many other molecules that contribute to cytotoxicity, thereby highlighting the need for prior fractionation. 
A. absinthium is used in Cuban folk medicine as a febrifuge and an antiparasitic (Roig 1974); similar uses have also been reported in other countries (Quinlan et al. 2002). Antiprotozoal activity of $A$. absinthium has been demonstrated against Naegleria fowleri (Mendiola et al. 1991), P. falciparum (Rodríguez et al. 2006) and Giardia lamblia (Guerra et al. 2001). No previous reports could be found of $A$. absinthium antileishmanial or antitrypanosomal potential, except for essential oils extracted from different Artemisia species showing activity against Leishmania tropica and Leishmania major (Hatimi et al. 2001). Although we detect for the first time some in vitro antitrypanosomal activity of this Cuban plant, non-selective action against all tested protozoa, including P. falciparum was found. Antibacterial and antifungal activities of Artemisia species have been reported after study of their essential oils (Blagojevic et al. 2006). Antimicrobial activity of an ethanolic extract of $A$. absinthium grown in Cuba was studied previously by Guerra et al. (2001). These authors reported MIC values against $S$. aureus, E. coli and C. albicans in a range of $13-26 \mathrm{mg} / \mathrm{mL}$, a dose range which is unrealistically high. In the present study, we obtained $\mathrm{IC}_{50}$ values of $>64 \mu \mathrm{g} / \mathrm{mL}$ for the same microorganisms, which clearly confirms lack of antimicrobial activity. Further studies on this extract are therefore not justified.

M. leucadendron has been considered useful in Cuba in places with high prevalence of malaria and has been used as an antiparasitic, antiseptic and insect repellent (Roig 1974). Traditional uses for Melaleuca species in other countries include applications as antiseptic, antihelminthic and skin parasiticide (Roig 1974, Budhiraja et al. 1999). Studies on anti-infective properties have been done using essential oils. In the present work, we studied the ethanolic extract of the plant branches and could only demonstrate significant inhibition of $T$. bru$c e i$ with an $\mathrm{IC}_{50}$ of about $4 \mu \mathrm{g} / \mathrm{mL}$. Mikus et al. (2000), studying in vitro effects of Melaleuca alternifolia essential oils against $L$. major and T. brucei, detected selective activity ( $\mathrm{SI}=50-80)$, but only against trypanosomes using HL-60 cells as reference. Our selectivity index was much lower $(\mathrm{SI}=4.84)$, but since we tested a crude extract, selectivity may improve after further fractionation. This extract can be considered as relatively-non toxic with a $\mathrm{CC}_{50}$ value of $20 \mu \mathrm{g} / \mathrm{ml}$. About antibacterial activity, Hussein et al. (2007) reported activity of Melaleuca ericifolia leaves extract whereas Farag et al. (2004) showed that all essential oils extracted from four different Melaleuca species, including M. leucadendron, vary in composition but possess antibacterial and antifungal activities. We detected some activity against $M$. canis $\left(\mathrm{IC}_{50}\right.$ $=13 \mu \mathrm{g} / \mathrm{mL}$ ). The observed activity against $T$. brucei and $M$. canis could justify further follow-up on fractions to check whether a gain of activity could be obtained.

S. glauca has been used by the Cuban population as febrifuge, antidysenteric, antiherpetic and antihelminthic (Roig 1974). Similar properties have been described in other Latin American countries (Roig 1974), the antiprotozoal (Franssen et al. 1997) and antibacterial (Caceres et al. 1990) activities. Our study revealed a strong inhibitory activity against all protozoa tested, but without selectivity. The strong antimalarial activity mentioned in previous published studies (Rodríguez et al. 2006) must therefore be interpreted with great caution. A significant cytotoxicity observed in the present study was also reflected in a toxic action after intraperitoneal injection in mice (Rodríguez et al. 2006). Several constituents have been isolated from Simaroubaceae, mainly alkaloids with high cytotoxicity and quassinoids with antimalarial and cytotoxic characteristics (Nurhanan et al. 2005). The antiplasmodial and cytotoxic properties of quassinoids are both linked to protein synthesis inhibition (Fukamiya et al. 2005), and it is likely that parasite and host cell ribosomes are too similar to allow for the development of selective inhibitors (Wright 2005). Because some quassinoids have shown greater selectivity against $P$. falciparum than against cellular lines, chemical derivation has attracted much attention as supplying potential leads for drug design (Guo et al. 2005). Based on eurycomanone structure, a monoacetylated derivative with reduced toxicity and potent inhibitory activity of a chloroquine-resistant $P$. falciparum strain was synthesized by Chan et al. (2005). Nevertheless, our results strongly support the view that the $S$. glauca extract should not become a priority for further follow-up, since all the observed activities are considered as non-specific. The activity obtained against $M$. canis $\left(\mathrm{IC}_{50}=2 \mu \mathrm{g} / \mathrm{mL}\right.$ ) is also likely to be related to non-specificity. Accurate interpretation of the activity results can only be obtained through fractionation of the crude extract and checking whether segregation between toxicity and specific activity will occur in particular fractions.

In conclusion, this study clearly demonstrates the value of integrated evaluation of extracts with partic-ular reference to cytotoxicity and selectivity evaluation to allow proper interpretation of screening results. The lack of selectivity data in many published reports precludes proper interpretation and endorses the need for appropriate and validated screening methods (Cos et al. 2006). In this study, the extract of M. leucadendron was found marginally active against $T$. b. brucei and may warrant further fractionation studies. The S. glauca extract, although intrinsically much more active in the different models, should not be withheld for further follow-up because of the high level of non-specificity.

\section{REFERENCES}

Abreu J, Scull R, Miranda M, Cuellar A, Fuentes V, Acosta L, Sánchez LM, Campos M, Torres MA, Hernández LM, López R 2004. La flora medicinal de Cuba, In J Abreu, R Scull, M Miranda, A Cuellar, V Fuentes, L Acosta, LM Sánchez, M Campos, MA Torres, LM Hernández, R López, Plantas medicinales, Ed. Abril, La Habana, Cuba, p. 7-10.

Blagojevick P, Radulovic N, Palic R, Stojanovic G 2006. Chemical composition of the essential oils of serbian wild-growing Artemisia absinthium and Artemisia vulgaris. J Agric Food Chem 54: 4780-4789.

Budhiraja SS, Cullum ME, Sioutis SS, Evangelista L, Habanova ST 1999. Biological activity of Melaleuca alternifolia (Tea Tree) oil component, terpenin-4-01, in human myelocytic cell line HL-60. J Manipulative Physiol Ther 22: 447-453.

Caceres A, Cano O, Samayoa B, Aguilar L 1990. Plants used in Guate- 
mala for the treatment of gastrointestinal disorders. 1. Screening of 84 plants against enterobacteria. $J$ Ethnopharmacol 30: 55-73.

Chan KL, Choo CY, Abdullah NR 2005. Semisynthetic 15-O-acyl and 1.5-di-O-acylerycomanones from Eurycoma longifolia as potential antimalarials. Planta Med 71: 967-969.

Cos P, Vlietinck AJ, Berghe DV, Maes L 2006. Anti-infective potential of natural products: How to develop a stronger in vitro "proofof- concept'. J Ethnopharmacol 106: 290-302.

Dua VK, Ojha VP, Roy R, Joshi BC, Valecha N, Usha Devi C, Bhatnagar MC, Sharma VP, Subbarao SK 2004. Anti-malarial activity of some xanthones isolated from the roots of Andrographis paniculata. J Ethnopharmacol 95: 247-251.

Farag RS, Shalaby AS, El Baroty GA, Ibrahim NA, Ali MA, Hassan EM 2004. Chemical and biological evaluation of the essential oils of different Melaleuca species. Phytother Res 18: 30-35.

Franssen FFJ, Smeijsters LJJW, Berger I, Medinilla Aldana BE 1997. In vivo and in vitro antiplasmodial activities of some plants traditionally used in Guatemala against malaria. Antimicrob Agents Chemother 41: 1500-1503.

Fukamiya N, Lee KH, Muhammad I, Murakami C, Okano M, Harvey I, Pelletier J 2005. Structure-activity relationships of quassinoids for eukaryotic protein synthesis. Cancer Lett 220: 37-48.

Guerra M, Torres D, Martínez L 2001. Validación del uso tradicional de plantas medicinales cultivadas en Cuba. Rev Cubana Plant Med 2: 48-51.

Guo Z, Vangapandu S, Sindelar RW, Walker LA, Sindelar RD 2005. Biologically active quassinoids and their chemistry: Potential Leads for Drug Design. Curr Med Chem 12: 173-190.

Hatimi S, Boudoma M, Bichichi M, Chaib N, Idrissi NG 2001. In vitro evaluation of antileishmania activity of Artemisia herba alba Asso. Bull Soc Pathol Exot 94: 29-31.
Hussein SA, Hashim AN, El-Sharawy RT, Sellem MA, Linscheld M, Lindequist L, Nawwar MA 2007. Ericifolin: An eugenol 5-Ogalloylglucoside and other phenolics from Melaleuca ericifolia. Phytochemistry 68: 1464-1470.

Mendiola J, Bousa M, Pérez N, Hernández H, Torres D 1991. Extracts of Artemisia abrotanum and Artemisia absinthium inhibit growth of Naegleria fowleri in vitro. Trans $R$ Soc Trop Med Hyg 85: 78-79.

Mikus J, Harkenthal M, Steverding D, Reichling J 2000. In vitro effect of essential oils and isolated mono- and sesquiterpenes on Leishmania major and Trypanosoma brucei. Planta Med 66: 366-368.

MSP-Ministerio de Salud Pública 1991. Medicamentos de origen vegetal: extractos y tinturas: proceso tecnológico. Norma Ramal de Salud Pública (NRSP) 311, MINSAP, Cuba, 23 pp.

Nurhanan MY, Azimahtol Hawariah LP, Mohd Ilham A, Mohd Shukri MA 2005. Cytotoxic effects of the root extracts of Eurycoma longifolia Jack. Phytotherapy Res 19: 994-996.

Pink R, Hudson A, Mouries MA, Bendig M 2005. Opportunities and challenges in antiparasitic drug discovery. Nat Rev Drug Discov 4: 727-740.

Quinlan MB, Quinlan RJ, Nolan JM 2002. Ethnophysiology and herbal treatments of intestinal worms in Dominica, West Indies. J Ethnopharmacol 80: 75-83.

Rodríguez M, Martínez JM, Rivero LR, Alvarez HMH, Valdez AFC, Rodríguez DA, Lizama RS, Payrol JA 2006. Evaluación de la actividad antimalárica de algunas plantas utilizadas en la medicina tradicional cubana. Rev Ciênc Farm Básica Apl 27: 197-205.

Roig JT 1974. Plantas medicinales, aromáticas o venenosas de Cuba, Ed. Científico-Técnica, La Habana, Cuba, 1125 pp.

Wright CW 2005. Traditional antimalarials and development of novel antimalarial drugs. J Ethnopharmacol 100: 67-71. 